\title{
Visual and Optical Performances of Multifocal Intraocular Lenses with Three Different Near Additions: 6-Month Follow-Up
}

\author{
Mengmeng Wang ${ }^{1}$, Christine Carole C. Corpuz ${ }^{1}$, Megumi Fujiwara ${ }^{1}$ and Minoru Tomita ${ }^{*}, 1,2,3$ \\ ${ }^{1}$ Shinagawa LASIK Center, Tokyo, Japan \\ ${ }^{2}$ Department of Ophthalmology, Wenzhou Medical College, Wenzhou, China \\ ${ }^{3}$ Tomita Minoru Eye Clinic Ginza, Tokyo, Japan
}

\begin{abstract}
Purpose: To compare the visual and optical outcomes of four multifocal intraocular lenses (IOLs) with three different near additions of +3.00 diopters (D), $+3.75 \mathrm{D}$ and $+4.00 \mathrm{D}$.

Methods: In this prospective study, 133 eyes of 88 patients were implanted with one of the following IOLs: AcrySof ${ }^{\oplus}$ ReSTOR $^{\oplus}$ SN6AD1 (+3.00 D) for Group A, Acriva ${ }^{\text {UD }}$ Reviol BB MF 613 or BB MFM 611 (+3.75 D) for Group B, and AcrySof ${ }^{\circledast}$ ReSTOR $^{\oplus}$ SN6AD3 (+4.00 D) for Group C. The visual acuity, refraction, intraocular pressure, tomography and corneal endothelial cell density (ECD) were compared between the three groups preoperatively and at 6 month postoperatively. Defocus curve, contrast sensitivity and higher order aberrations (HOAs) at 6 month postoperative visit were measured and compared.

Results: There were no statistically significant differences in distance visual acuity, refraction, intraocular pressure or ECD among the three groups after 6 months $(P>0.05)$. The photopic contrast sensitivity in Group $\mathrm{C}$ was statistically better than in Group A $(P<0.05)$. The scotopic ocular aberration in Group B was statistically greater compared to that in Group A $(P<0.05)$. The highest near-visual peaks were $-0.06 \operatorname{logMAR}$ at a $-2.50 \mathrm{D}(40 \mathrm{~cm})$ in Group A, $-0.07 \log$ MAR at $-3.00 \mathrm{D}(33 \mathrm{~cm})$ in Group B, and $-0.06 \log \mathrm{MAR}$ at $-3.50 \mathrm{D}(29 \mathrm{~cm})$ in Group C. Statistically significant differences in near and intermediate visual acuities were observed among the three groups at $-2.00 \mathrm{D}(50 \mathrm{~cm}),-2.50 \mathrm{D}(40 \mathrm{~cm}),-3.50 \mathrm{D}$ $(29 \mathrm{~cm})$ and $-4.00 \mathrm{D}(25 \mathrm{~cm})(P<0.01)$.

Conclusion: AcrySof ${ }^{\circledast}$ ReSTOR ${ }^{\circledast}$ SN6AD1 IOLs (+3.00 D) and SN6AD3 (+4.00 D) IOLs provided the best intermediate and near vision, respectively. Both intermediate and near vision were comparatively better in the eyes with Acriva ${ }^{\mathrm{UD}}$ Reviol BB MFM 611 IOLs or BB MF 613 IOLs (+3.75 D).
\end{abstract}

Keywords: Cataract surgery, multifocal intraocular lens, near addition.

\section{INTRODUCTION}

Multifocal intraocular lens (IOL) implantation is a popular presbyopia-correcting strategy to reduce dependence on reading spectacles by providing adequate vision over a range of distances [1-3]. Nowadays, several designs of multifocal IOL with range of near additions, such as +3.00 diopter (D), $+3.50 \mathrm{D},+3.75 \mathrm{D}$, or $+4.00 \mathrm{D}$, are available [4, 5]. In previous studies, the AcrySof ${ }^{\circledast}$ ReSTOR $^{\circledast}$ SN6AD1 IOL (Alcon Corp., Fort Worth, Texas, United States) and Acry-Sof ${ }^{\oplus}$ ReSTOR $^{\circledast}$ SN6AD3 IOL (Alcon Corp., Fort Worth, Texas, United States) with near additions of +3.00 D and $+4.00 \mathrm{D}$ have been demonstrated to be efficient aspheric IOL models [6, 7]. Acriva ${ }^{\mathrm{UD}}$ Reviol (VSY Biotechnology, Amsterdam, Netherlands) is a recent addition to the diffractive multifocal intraocular lens designs with $+3.75 \mathrm{D}$ near add power which is available in two models: BB MF 613 and BB MFM 611. Having the identical optic design,

*Address correspondence to this author at the Tomita Minoru Eye Clinic Ginza, 4-12-19 Nishoukousan BLDG 4F Ginza, Chuoku-Tokyo, 104-0061, Japan; Tel: +81-36228-4200; Fax: +81-36228-4201;

E-mail: tomita@eyecanmedical.com these two models claim to yield satisfactory far, intermediate and near vision; the BB MFM 611 model is previously been shown to provide effective visual acuities and contrast sensitivities [8]. The aim of the current study is to evaluate and compare the visual and optical performances of eyes implanted with four multifocal IOL models having three different near additions, +3.00 diopters (D) $\left(\right.$ AcrySof $^{\mathrm{B}}$ ReSTOR $^{\circledR}$ SN6AD1), +3.75 D (Acriva ${ }^{\mathrm{UD}}$ Reviol BB MF 613 and BB MFM 611) or +4.00 D (AcrySof ${ }^{\circledR}$ ReSTOR $^{\circledR}$ SN6AD3).

\section{PATIENTS AND METHODS}

\section{Study Design}

This prospective single-center study comprised of cataract patients who underwent routine phacoemlsification with multifocal IOL implantation between the period January 2009 and December 2012 at the Shinagawa LASIK Center, Tokyo, Japan. Patients with either incipient or moderate cataract causing a significant reduction in visual qualities were included in the study. Presence of ocular pathology other than cataract, previous intraocular surgery, and significant corneal aberrations were exclusion criteria. One hundred and thirty-three eyes of 88 patients (58 women 
and 30 men) were recruited. The sample eyes were randomly divided into three groups: Group A eyes received multifocal IOLs with AcrySof ${ }^{\oplus}$ ReSTOR ${ }^{\circledR}$ SN6AD1 IOLs (+3.00 D); Group B eyes received Acriva ${ }^{\text {UD }}$ Reviol BB MF 613 or BB MFM 611 IOLs (+3.75 D); Group C eyes received AcrySof ${ }^{\circledast}$ ReSTOR ${ }^{\circledR}$ SN6AD3 IOLs (+4.00 D). Group A consisted of 29 eyes from 19 patients; Group B, 42 eyes from 30 patients; and Group C, 62 eyes from 39 patients. All subjects read and signed informed consent that explained the surgical procedure, possible risks, and their rights. The study was performed in accordance with the ethics codes established by the Ethical Board Committee in Japan.

\section{Multifocal IOLs}

Table 1 summarizes the specifications of each multifocal IOL used. All IOL models have a $6.0 \mathrm{~mm}$ optic zone. Aspheric surfaces are designed to produce negative spherical aberration to compensate for the positive spherical aberration of the cornea. Both AcrySof ${ }^{\circledR}$ ReSTOR $^{\circledR}$ SN6AD1 and AcrySof $^{\circledast}$ ReSTOR $^{\circledast}$ SN6AD3 consist of peripheral refractive zone and $3.6 \mathrm{~mm}$ apodized diffractive central design. The corresponding diffractive structures of the AcrySof $^{\circledast}$ ReSTOR $^{\circledR}$ SN6AD1 and AcrySof ${ }^{\circledast}$ ReSTOR $^{\circledR}$ SN6AD3 have 9 and 12 steps, providing near additions of $+3.00 \mathrm{D}$ and $+4.00 \mathrm{D}$, respectively. Acriva ${ }^{\mathrm{UD}}$ Reviol BB MF 613 and BB MFM 611 have different diffractive ring distributions for intermediate and near vision with $+3.75 \mathrm{D}$ near addition.

\section{Surgical Technique}

The IOLMaster (Carl Zeiss Meditec, Jena, Germany) was used for preoperative biometry and IOL power calculations. Femtosecond laser (Catalys ${ }^{\text {TM }}$ Precision Laser System, Optimedica Corp., Sunnyvale, California, United States) was routinely used for the continuous curvilinear capsulorrhexis (CCC) and lens fragmentation [9]. Phacoemulsification was performed using Infinity phacoemulsification machine (Alcon Corp., Fort Worth, Texas, United States). The steepest corneal meridian was selected for the surgical incision. After aspirating the residual cortex, study assigned multifocal IOL was implanted into the intact capsular bag. All surgeries were performed by the same surgeon (M.T.).

\section{Postoperative Treatments}

In all cases, post-operative medications comprised a 500 $\mathrm{mg}$ oral levofloxacin (Daiichi Sankyo, Cravit ${ }^{\mathrm{TM}}$, Tokyo, Japan) once a day for three days, $0.1 \%$ diclofenac sodium eye drops (Nitto Medic, Toyama, Japan), $0.1 \%$ dexamethasone metasulfobenzoate sodium (Nitto Medic, D $\cdot \mathrm{E} \cdot \mathrm{X}^{\mathrm{TM}}$, Toyama, Japan), and $0.5 \%$ moxifloxacin hydrochloride (Alcon Corp., Vegamox ${ }^{\mathrm{TM}}$, Fort Worth, Texas, United States) 5 times a day for 1 week. The diclofenac was reduced to 4 times a day for 1 month after first week. Latter two were switched to topical $0.1 \%$ fluorometholone ophthalmic suspension (Nitto Medic, Toyama, Japan) and $0.3 \%$ ofloxin ophthalmic solution (Nitto Medic, Toyama, Japan) 4 times a day for up to 1 month and discontinued thereafter.

\section{Preoperative and Postoperative Examinations}

Patients were examined preoperatively and at 1day, 7 days, 1 month, 3 months and 6 months postoperatively. Uncorrected and corrected near and distance visual acuities (UDVA) were measured at all postoperative visits by the same masked optometrist. Clinical refraction was performed at each visit using sphere, cylinder, and manifest spherical equivalent (MRSE) notations. Defocus curve was obtained using a previously reported method [10-12]. Visual acuities were converted to $\log$ MAR for statistical analysis. Contrast sensitivity was measured using the Takagi ${ }^{\mathrm{TM}}$ Contrast Glare Tester CGT-1000 (Takagi Seiko, Nagano-Ken, Japan) with best spectacle correction under photopic (illumination of 21 candela $(\mathrm{cd}) / \mathrm{m}^{2}$ ) and scotopic (illumination of $11 \mathrm{~cd} / \mathrm{m}^{2}$ ) conditions [13]. Wave-Front Analyzer ${ }^{\mathrm{TM}}$ KR-1W (Topcon Corp., Tokyo, Japan) was utilized to measure higher order aberrations (HOAs) under photopic (4-mm pupil diameter) and scotopic (6-mm pupil diameter) conditions. Postoperative complications, if any, were evaluated using

Table 1. Intraocular lens characteristics.

\begin{tabular}{|c|c|c|c|c|}
\hline & $\begin{array}{c}\text { AcrySof }^{\circledR} \\
\text { ReSTOR }^{\circledast} \\
\text { SN6AD1 }\end{array}$ & $\begin{array}{c}\text { Acriva }^{\text {UD }} \\
\text { Reviol } \\
\text { MF 613 }\end{array}$ & $\begin{array}{c}\text { Acriva }^{\text {UD }} \\
\text { Reviol } \\
\text { MFM } 611\end{array}$ & $\begin{array}{c}\text { AcrySof }^{\circledast} \\
\text { ReSTOR }^{\circledast} \\
\text { SN6AD3 }\end{array}$ \\
\hline Type & Diffractive-refractive & Diffractive & Diffractive & Diffractive-refractive \\
\hline Profile & Aspheric & Aspheric & Aspheric & Aspheric \\
\hline Addition & +3.00 Diopters(D) & $+3.75 \mathrm{D}$ & $+3.75 \mathrm{D}$ & $+4.00 \mathrm{D}$ \\
\hline Optic zone & $6.0 \mathrm{~mm}$ & $6.0 \mathrm{~mm}$ & $6.0 \mathrm{~mm}$ & $6.0 \mathrm{~mm}$ \\
\hline Light distribution & $\begin{array}{l}40-90 \% \text { of light to } \\
\text { distance focus }\end{array}$ & $\begin{array}{l}65 \% \text { of light to } \\
\text { distance focus }\end{array}$ & $\begin{array}{l}65 \% \text { of light to } \\
\text { distance focus }\end{array}$ & $\begin{array}{l}40-90 \% \text { of light to } \\
\text { distance focus }\end{array}$ \\
\hline Haptic design & $\mathrm{C}$ & $\mathrm{C}$ & Plate & $\mathrm{C}$ \\
\hline Overall diameter & $13.0 \mathrm{~mm}$ & $13.0 \mathrm{~mm}$ & $11.0 \mathrm{~mm}$ & $13.0 \mathrm{~mm}$ \\
\hline Range & $+6.00 \mathrm{D}$ to $+34.00 \mathrm{D}$ & $0.00 \mathrm{D}$ to $+45.00 \mathrm{D}$ & $0.00 \mathrm{D}$ to $+45.00 \mathrm{D}$ & $+6.00 \mathrm{D}$ to $+34.00 \mathrm{D}$ \\
\hline Material & Hydrophobic acrylate & $\begin{array}{l}\text { Hydrophilic acrylic }(25 \%) \\
\text { with hydrophobic surface }\end{array}$ & $\begin{array}{l}\text { Hydrophilic acrylic ( } 25 \%) \\
\text { with hydrophobic surface }\end{array}$ & $\begin{array}{l}\text { Hydrophobic } \\
\text { acrylate }\end{array}$ \\
\hline Blue filter & Yes & No & No & Yes \\
\hline A-constant & 118.9 & 118.0 & 118.0 & 118.9 \\
\hline
\end{tabular}


comprehensive ocular examinations that included slit lamp biomicroscopy, funduscopy, intraocular pressure (Computerized Tonometer, Topcon, Japan), tomography (Pentacam ${ }^{\mathrm{TM}}$, Oculus Optikgeräte $\mathrm{GmbH}$, Wetzlar, Germany) and corneal endothelial cell count (Noncon Robo ${ }^{\mathrm{TM}}$ FA3609; Konan Medical, Irvine, California, USA) [14].

\section{Statistical Analysis}

Statistical analysis was performed with JMP 9 statistical package (SAS Institute, Inc., Cary, NC, USA) software. Descriptive statistical results are presented as mean and standard deviation. Categorical variables were compared using the Pearson's chi-square test. Where applicable, Oneway Anova with Tukey's HSD test was used to compare the results among the three groups. The Kruskal-Wallis test with Steel-Dwass test was used to compare the three IOL groups for non-parametric variables. Results with $P<0.05$ were considered statistically significant.

\section{RESULTS}

Table 2 illustrates the preoperative characteristics of the eyes. There were no statistical differences between the groups in terms of gender, age, IOL power, UDVA, sphere, cylinder, MRSE, UNVA, intraocular pressure or corneal endothelial cell density (ECD) preoperatively $(P>0.05)$. The mean values of CDVA and CNVA in Group B eyes were statistically significantly better than in the eyes of Group C ( $P=0.0258$ and $P=0.0266$, respectively).

Table 3 shows 6-month postoperative conditions of the eyes No statistical differences were observed for UDVA, CDVA, sphere, cylinder, MRSE, intraocular pressure or corneal endothelial cell density among the three groups $(P>$ 0.05). The mean values of UNVA and CNVA in the eyes of Group C were significantly better than in the eyes of Group A $(P=0.0284$ and $P=0.0062$, respectively $)$.

Defocus curves of the three groups at 6-month postoperatively are illustrated in Fig. (1). There was no statistically significant difference in visual acuities among the three groups when the defocus level was more than -1.50 $\mathrm{D}(67 \mathrm{~cm}$ and beyond). The highest near-visual peaks were $0.06 \log$ MAR at a defocus level of $-2.50 \mathrm{D}(40 \mathrm{~cm})$ in Group A, $-0.07 \log$ MAR at $-3.00 \mathrm{D}(33 \mathrm{~cm})$ in Group B, and -0.06 $\log$ MAR at $-3.50 \mathrm{D}(29 \mathrm{~cm})$ in Group C. The differences in visual acuity between the viewing distance range of $-2.50 \mathrm{D}$ $(40 \mathrm{~cm})$ and $-2.00 \mathrm{D}(50 \mathrm{~cm})$ were statistically significant $(P$ $<0.0001)$. The visual acuities in Group B were significantly better than those in Group $\mathrm{C}(P<0.05)$, but statistically worse than those in Group A $(P<0.05)$.

Fig. (2) shows the 6-month postoperative performances in terms of contrast sensitivity of the eyes in the different groups. At a visual angle of 4.0 degrees, the photopic contrast of the eyes in Group C was statistically better than that in Group A $(P=0.0237)$. No other variables showed statistically significant differences among the groups under photopic or mesopic condition $(P>0.05)$.

There was no statistically significant difference $(P>$ 0.05 ) in the corneal HOAs among the groups (Fig. 3). Under the scotopic condition (6-mm pupil diameter), ocular S6 of Group B was statistically greater than in Group A eyes $(P=$ $0.0317)$. No other components of corneal and coular HOA aberrations showed a statistical difference among the groups under photopic or mesopic conditions $(P>0.05)$.

\section{DISCUSSION}

Unlike monofocal IOLs, multifocal IOLs can avoid the postoperative monovision and presbyopia in pseudophakic eyes. Multifocal IOLs could simultaneously provide practically good near, intermediate and distance vision through their refractive or diffractive optical designs with one or multiple addition powers [15]. In this study, three different near additions $(+3.00 \mathrm{D},+3.75$ $\mathrm{D}$ and $+4.00 \mathrm{D}$ ) in four multifocal IOL designs were compared for their efficacy. The outcome information may be invaluable in choosing the suitable multifocal IOL models for a patient.

Table 2. Preoperative conditions of the three groups.

\begin{tabular}{|c|c|c|c|c|c|c|c|}
\hline Parameters & $\begin{array}{l}\text { Group A } \\
(+3.00 D)\end{array}$ & $\begin{array}{l}\text { Group B } \\
(+3.75 D)\end{array}$ & $\begin{array}{l}\text { Group C } \\
(+4.00 D)\end{array}$ & $\begin{array}{c}P \text { Values } \\
\text { Among Three } \\
\text { Groups }\end{array}$ & \multicolumn{3}{|c|}{$P$ Values of Post Hoc Comparison } \\
\hline Age, years & $61.39 \pm 6.53$ & $60.60 \pm 6.63$ & $61.53 \pm 5.43$ & 0.6490 & & & \\
\hline IOL power, $\mathrm{D}$ & $18.07 \pm 5.15$ & $15.39 \pm 6.37$ & $16.35 \pm 6.23$ & 0.2800 & & & \\
\hline CDVA, LogMAR & $0.06 \pm 0.18$ & $0.01 \pm 0.19$ & $0.07 \pm 0.17$ & 0.0312 & NS & NS & 0.0258 \\
\hline Sphere, D & $-1.43 \pm 5.54$ & $-3.02 \pm 5.25$ & $-2.86 \pm 5.02$ & 0.2547 & & & \\
\hline Cylinder, D & $-1.06 \pm 0.79$ & $-0.85 \pm 0.63$ & $-0.95 \pm 0.68$ & 0.7300 & & & \\
\hline MRSE, D & $-1.96 \pm 5.41$ & $-3.44 \pm 5.27$ & $-3.33 \pm 5.11$ & 0.3494 & & & \\
\hline $\mathrm{ECD}$, cells $/ \mathrm{mm}^{2}$ & $2749.21 \pm 305.65$ & $2717.60 \pm 346.45$ & $2704.11 \pm 322.92$ & 0.7848 & & & \\
\hline
\end{tabular}

UDVA, uncorrected distance visual acuity; CDVA, corrected distance visual acuity; MRSE, manifest refraction spherical equivalent; UNVA, uncorrected near visual acuity; CNVA, corrected near visual acuity; D, diopter; IOP, intraocular pressure; ECD, corneal endothelial cell density; NS, no significance. $P$, statistical difference among the three groups. 
Table 3. Six-month postoperative conditions of the three groups.

\begin{tabular}{|c|c|c|c|c|c|c|c|}
\hline \multirow{2}{*}{ Parameters } & \multirow{2}{*}{$\begin{array}{l}\text { Group A } \\
(+3.00 D)\end{array}$} & \multirow{2}{*}{ Group B (+3.75D) } & \multirow{2}{*}{ Group C (+4.00D) } & \multirow{2}{*}{$\begin{array}{c}P \text { Values } \\
\text { Among } \\
\text { Three Groups }\end{array}$} & \multicolumn{3}{|c|}{$P$ Values of Post Hoc Comparison } \\
\hline & & & & & $\mathrm{A} v s \mathrm{~B}$ & A vs $\mathrm{C}$ & $\mathrm{B}$ vs $\mathrm{C}$ \\
\hline UDVA, LogMAR & $-0.02 \pm 0.13$ & $-0.05 \pm 0.10$ & $0.00 \pm 0.13$ & 0.3339 & & & \\
\hline CDVA, LogMAR & $-0.16 \pm 0.04$ & $-0.14 \pm 0.07$ & $-0.16 \pm 0.04$ & 0.3341 & & & \\
\hline Sphere, D & $0.82 \pm 0.50$ & $0.96 \pm 0.47$ & $0.78 \pm 0.53$ & 0.2800 & & & \\
\hline Cylinder, D & $-0.90 \pm 0.48$ & $-0.64 \pm 0.53$ & $-0.71 \pm 0.40$ & 0.0903 & & & \\
\hline MRSE, D & $0.38 \pm 0.47$ & $0.64 \pm 0.45$ & $0.43 \pm 0.48$ & 0.0628 & & & \\
\hline UNVA, LogMAR & $0.21 \pm 0.17$ & $0.18 \pm 0.14$ & $0.12 \pm 0.14$ & 0.0129 & NS & 0.0284 & NS \\
\hline CNVA, LogMAR & $0.01 \pm 0.03$ & $0.03 \pm 0.10$ & $0.00 \pm 0.02$ & 0.0062 & NS & 0.0062 & NS \\
\hline IOP, mmHg & $10.26 \pm 2.58$ & $11.14 \pm 2.55$ & $11.52 \pm 2.69$ & 0.1513 & & & \\
\hline $\mathrm{ECD}$, cells $/ \mathrm{mm}^{2}$ & $2656.09 \pm 318.36$ & $2365.00 \pm 380.13$ & $2573.07 \pm 388.28$ & 0.2751 & & & \\
\hline
\end{tabular}

UDVA, uncorrected distance visual acuity; CDVA, corrected distance visual acuity; MRSE, manifest refraction spherical equivalent; UNVA, uncorrected near visual acuity; CNVA, corrected near visual acuity; D, diopter; IOP, intraocular pressure; ECD, corneal endothelial cell density. $P$, statistical difference among the three groups; NS, no significance.

Excellent distance visual acuity was achieved in all study groups six months postoperatively. The mean UDVA and CDVA in all groups reached $0.00 \log$ MAR and -0.14 $\operatorname{logMAR}$ or better demonstrating a good efficiency of tested IOLs for distance vision. Similaroutcomes were reported previously [5-8]. de Vries et al. [6] reported mean UDVA and CDVA of $0.04 \log$ MAR and -0.04 $\log$ MAR in eyes implanted with AcrySof $^{\circledR}$ ReSTOR $^{\circledR}$ SN6AD1 IOLs, respectively. In eyes implanted with AcrySof ${ }^{\circledR} \operatorname{ReSTOR}^{\circledR}$
SN6AD3 IOLs, UDVA and CDVA were $0.14 \log$ MAR and $0.01 \log$ MAR, respectively. In another study by Izzet Can et al. [8], eyes implanted with Acriva ${ }^{\mathrm{UD}}$ Reviol BB MFM 611 IOLs achieved mean uncorrected distance visions of 0.07 $\log$ MAR and mean CDVA of $0.02 \log$ MAR. To the best of our knowledge, visual and optical outcome of Acriva ${ }^{\mathrm{UD}}$ Reviol BB MF 613 IOL models have not been reported. Furthermore, this is the first study comparing the differences in outcome for various models of IOLs.

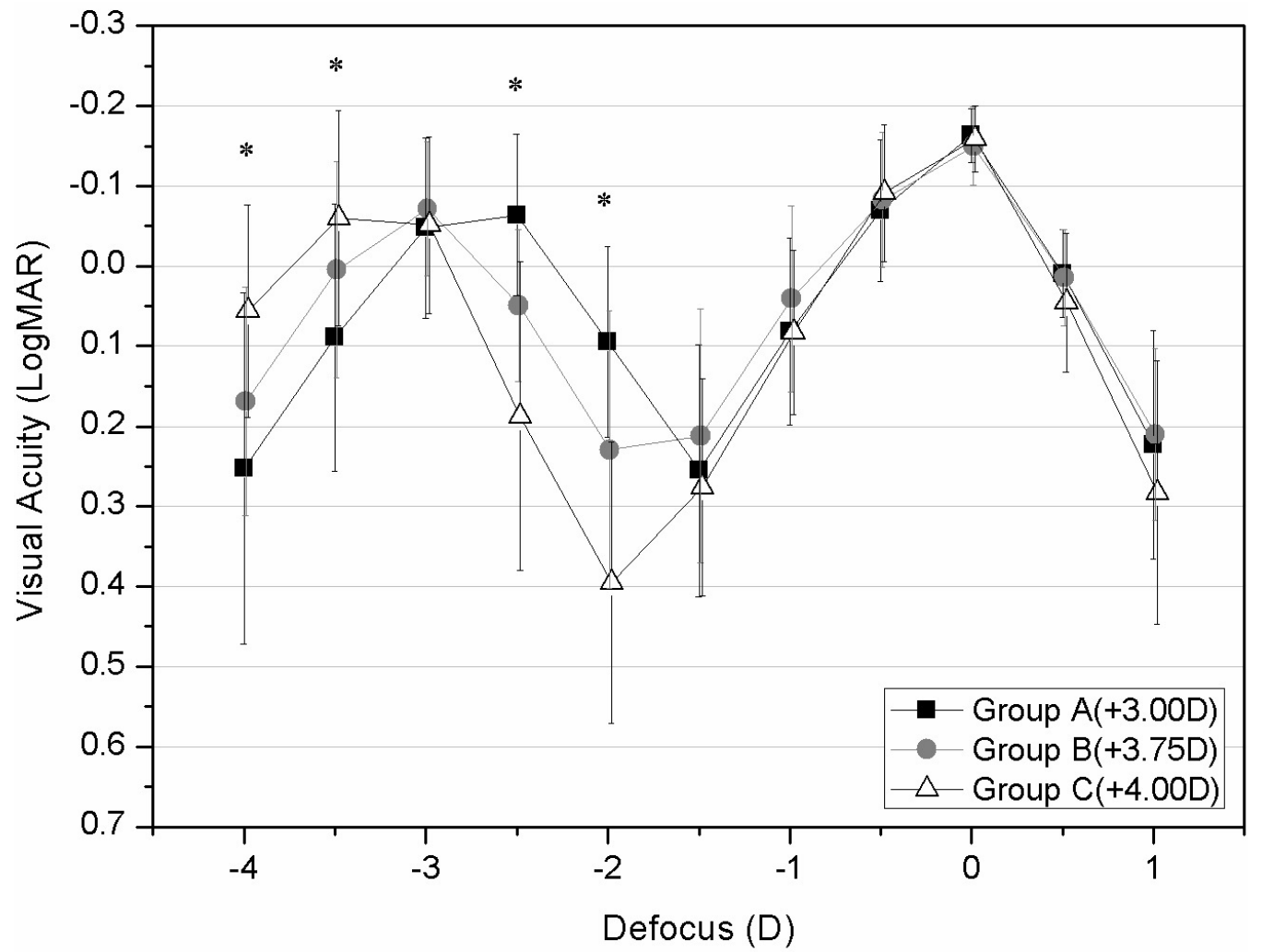

Fig. (1). Six-month postoperative visual acuity (mean and standard deviation) at different levels of defocus for three groups. $\quad$ *, significant different between thre groups $(\mathrm{P}<0.05)$. 


\section{Light on}

Light off

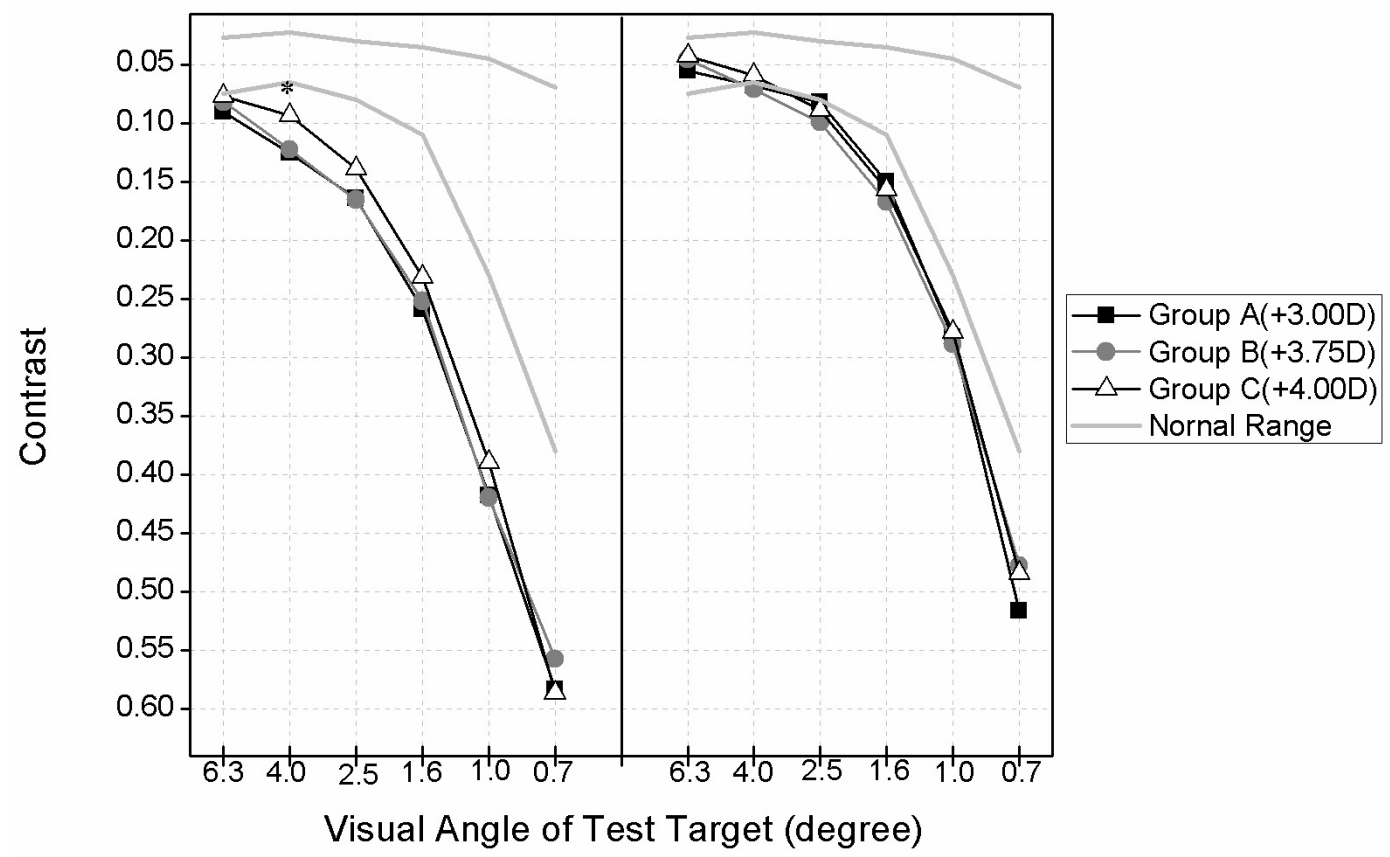

Fig. (2). Six-month postoperative contrast sensitivity under photopic (light on, 21 candela (cd) $/ \mathrm{m}^{2}$ ) and mesopic (light off, $11 \mathrm{~cd} / \mathrm{m}^{2}$ ) conditions of eyes implanted with different MIOLs. $\quad *$, significant different between thre groups $(\mathrm{P}<0.05)$.
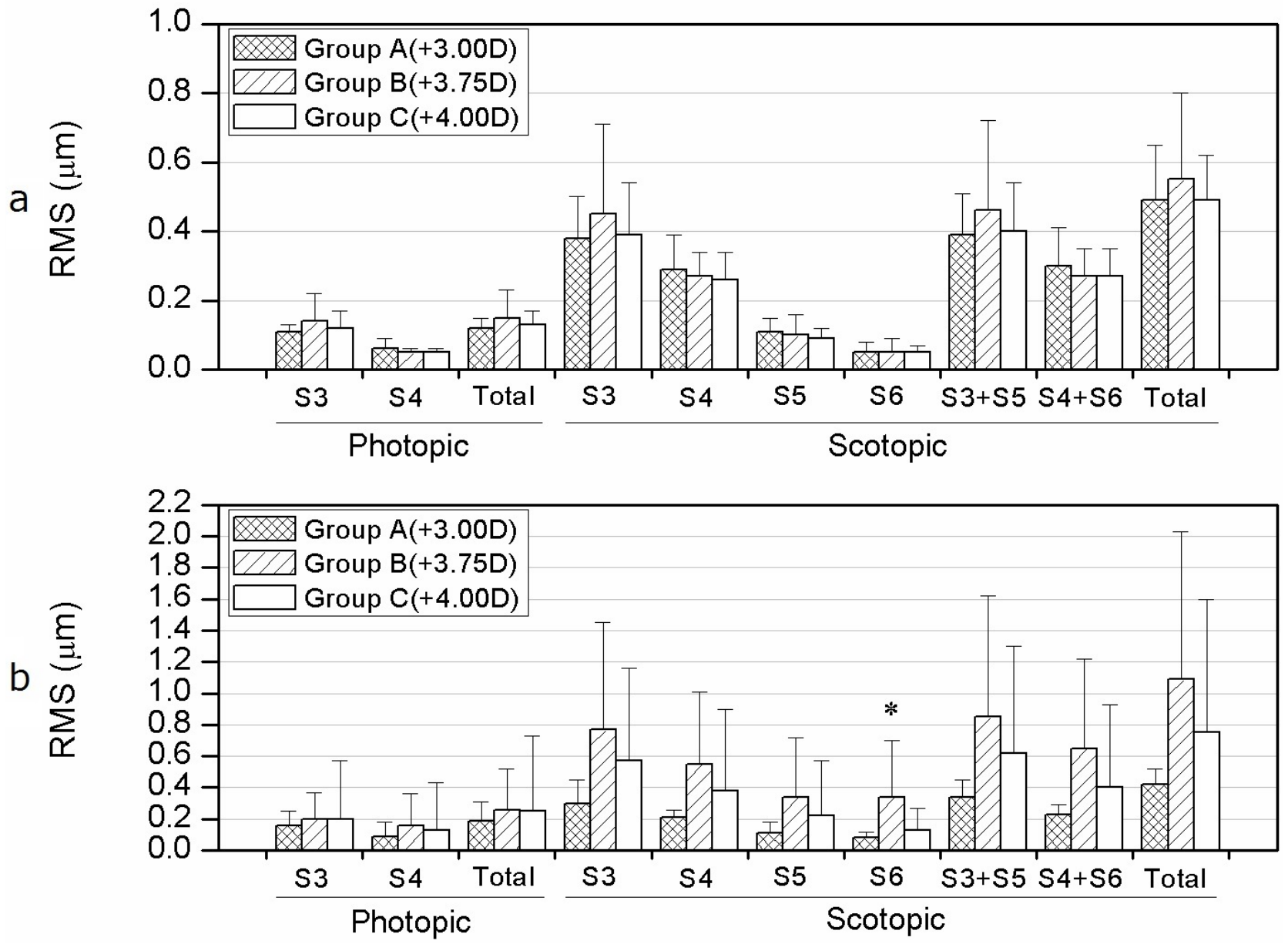

Fig. (3). Six-month postoperative high-order aberrations (HOAs) under photopic (4-mm pupil diameter) and mesopic (6-mm pupil diameter) conditions of eyes implanted with different MIOLs. a, the corneal HOAs of the eyes in three groups. b, the ocular HOAs of the eyes in three groups. $*$, significant different between thre groups $(\mathrm{P}<0.05)$. 
Unlike the similarity in distance visions, significant differences in near and intermediate visual acuities between the groups receiving different near add powers were observed. The mean UNVA and CNVA in eyes with any IOL model reached $0.21 \log$ MAR and $0.03 \log$ MAR or better. Statistically significant differences in both UNVA and CNVA were found between Group A and Group C. It should be noted that, near visual acuity was measured at a distance of $30 \mathrm{~cm}$ according to the custom in Japan [16], which was different from the $40 \mathrm{~cm}$ used in other countries.

To evaluate the visual behaviors of these multifocal IOL models at different viewing distances, a defocus curve was created by using different levels of defocus $[12,11,17]$. No difference was observed among the three groups in terms of visual acuities at a viewing distance range of $67 \mathrm{~cm}(-1.50$ D) and beyond $(P>0.05)$. The highest near-visual peak in Group A eyes (+3.00 D) located at a distance of $40 \mathrm{~cm}(-2.50$ D). AcrySof ${ }^{\circledast}$ ReSTOR $^{\circledR}$ SN6AD1 IOLs provided the best vision at a viewing distance ranging between $40 \mathrm{~cm}$ and 50 $\mathrm{cm}(-2.00 \mathrm{D})(P<0.0001)$. On the other hand, the highest near-visual peak in Group C eyes $(+4.00 \mathrm{D})$ were located at the distance of $29 \mathrm{~cm}\left(-3.50\right.$ D). AcrySof ${ }^{\circledast} \operatorname{ReSTOR}^{\circledR}$ SN6AD3 IOLs provided the best vision at a viewing distance ranging between $25 \mathrm{~cm}(-4.00 \mathrm{D})$ and $29 \mathrm{~cm}(P<0.01)$.

Acriva $^{\mathrm{UD}}$ Reviol BB MFM 611 or BB MF 613 IOLs likewise provided satisfactory distance, intermediate and near visions during the entire range of viewing distances. The highest near-visual peak in Group B eyes $(+3.75 \mathrm{D})$ was located at the distance of $33 \mathrm{~cm}(-3.00 \mathrm{D})$. Acriva ${ }^{\mathrm{UD}}$ Reviol BB MFM 611 or BB MF 613 IOLs provided better visions than $\mathrm{ReSTOR}^{\circledast}$ SN6AD3 IOLs at a viewing distance range between $40 \mathrm{~cm}$ and $50 \mathrm{~cm}(-2.00 \mathrm{D})(P<0.05)$. The best performance in intermediate vision among the three groups was observed in Group B (+3.75 D).

Previous studies have demonstrated that multifocal IOLs reduce the optical quality and negatively affect functional performance $[18,19]$. The postoperative contrast sensitivities in this study were consistently lower than that of the normal range, especially under the photopic conditions which might be due to increased straylight leading to reduced optical performance [20, 21]. Except for the 4.0 degrees of photopic condition, no statistically significant difference in contrast sensitivity was observed between the groups in the current study,. Similar outcomes were reported in previous studies $[6$, 22]. It appears that different optic designs of the multifocal IOL models studied in this study resulted comparable straylights effects.

Postoperative wavefront aberrations of the various multifocal IOL models were evaluated. Only statistical difference was observed for S6 component of the aberration $(P=0.0317)$; all other corneal or ocular HOAs under photopic or scotopic vision $(P>0.05)$ showed no difference between the groups. Nevertheless, since two or more wavefronts could be produced simultaneously when light passes through a multifocal IOL, there was no certainty which particular wavefront was being measured by the Hartmann-Shack sensors during the test [23]. We used the Wave-Front Analyzer ${ }^{\mathrm{TM}}$ to measure HOAs of the postoperative eyes [24]. The wavelength $(840 \mathrm{~nm})$ used in this technique which is longer than the visible wavelength that is used during the process of multifocal IOLs designing
[25]. Thus, we believe that the HOAs recorded in this study is likely to have represented the optical characteristics of the distance segment $[6,25]$.

In recent days, people are ever more dependent on the intermediate and near vision than before to perform close-up tasks, such as browsing internet and reading messages on mobile phones. Since varieties of multifocal IOL models with different near additions are available, choosing a suitable one for a patient is often challenging. Although all models resulted in a satisfactory distance visions in the current study, difference in intermediate and near visual were observed. The authors believe that surgeons should consider patient's nature of near vision tasks. For instance, if a patient prefers performing tasks at arms' length, implantation of AcrySof ${ }^{\circledast}$ ReSTOR ${ }^{\circledast}$ SN6AD1 IOL may be recommended which offer good intermediate and distance vision. In contrast, if a patient is a handworker, a stronger near addition models such as AcrySof ${ }^{\circledast}$ ReSTOR ${ }^{\circledast}$ SN6AD3 IOLs may be advisable. While most of the patients would like to have an extended range clear vision, both Acriva ${ }^{\mathrm{UD}}$ Reviol BB MFM $611 \mathrm{IOL}$ and BB MF 613 IOL would be preferable.

\section{CONCLUSION}

In conclusion, multifocal IOL models with different near additions offered comparable distance visual outcome. While IOLs with $+3.00 \mathrm{D}$ (AcrySof ${ }^{\circledR}$ ReSTOR $^{\circledR}$ SN6AD1) and and +4.00 D (SN6AD3) additions provided the best intermediate and near vision, respectively, IOL with $+3.75 \mathrm{D}$ (Acriva ${ }^{\mathrm{UD}}$ Reviol BB MFM 611 and MF 613) offered better performance for both intermediate and near vision.

\section{CONFLICT OF INTEREST}

Dr. Tomita is a consultant for VSY Biotechnology Inc. The authors report no other conflict of interest in this work.

\section{ACKNOWLEDGEMENTS}

Declared none.

\section{REFERENCES}

[1] Dexl AK, Zaluski S, Rasp M, Grabner G. Visual performance after bilateral implantation of a new diffractive aspheric multifocal intraocular lens with a $3.5 \mathrm{D}$ addition. Eur J Ophthalmol 2013; 24(1): 35-43.

[2] Alió JL, Plaza-Puche AB, Montalban R, Javaloy J. Visual outcomes with a single-optic accommodating intraocular lens and a low-addition-power rotational asymmetric multifocal intraocular lens. J Cataract Refract Surg 2012; 38(6): 978-85.

[3] Lubiński W, Podboraczyńska-Jodko K, Gronkowska-Serafin J, Karczewicz D. Visual outcomes three and six months after implantation of diffractive and refractive multifocal IOL combinations. Klinika Oczna 2011; 113(7-9): 209-15.

[4] Rabsilber TM, Rudalevicius P, Jasinskas V, Holzer MP, Auffarth GU. Influence of $+3.00 \mathrm{D}$ and $+4.00 \mathrm{D}$ near addition on functional outcomes of a refractive multifocal intraocular lens model. J Cataract Refract Surg 2013; 39(3): 350-57.

[5] Alió JL, Grabner G, Plaza-Puche AB, et al. Postoperative bilateral reading performance with 4 intraocular lens models: 6-month results. J Cataract Refract Surg 2011; 37(5): 842-52.

[6] de Vries NE, Webers CA, Montés-Micó R, Ferrer-Blasco T, Nuijts RM. Visual outcomes after cataract surgery with implantation of a $+3.00 \mathrm{D}$ or $+4.00 \mathrm{D}$ aspheric diffractive multifocal intraocular lens: Comparative study. J Cataract Refract Surg 2010; 36(8): 1316-22.

[7] Toto L, Carpineto P, Falconio G, et al. Comparative study of Acrysof ReSTOR multifocal intraocular lenses +4.00 D and +3.00 D: Visual performance and wavefront error. Clin Exp Optom 2013; 96(3): 295-302. 
[8] Can I, Bostanc1 Ceran B, Soyugelen G, Takmaz T. Comparison of clinical outcomes with 2 small-incision diffractive multifocal intraocular lenses. J Cataract Refract Surg 2012; 38(1): 60-7.

[9] Conrad-Hengerer I, Hengerer FH, Schultz T, Dick HB. Effect of femtosecond laser fragmentation of the nucleus with different softening grid sizes on effective phaco time in cataract surgery. J Cataract Refract Surg 2012; 38(11): 1888-94.

[10] Buckhurst PJ, Wolffsohn JS, Naroo SA. Multifocal intraocular lens differentiation using defocus curves. Invest Ophthalmol Vis Sci 2012; 53(7): 3920-6.

[11] Gupta N, Wolffsohn JS, Naroo SA. Optimizing measurement of subjective amplitude of accommodation with defocus curves. J Cataract Refract Surg 2008; 34(8): 1329-38.

[12] Wolffsohn JS, Jinabhai AN, Kingsnorth A, et al. Exploring the optimum step size for defocus curves. J Cataract Refract Surg 2013; 39(6): 873-80.

[13] Pesudovs K. Takagi Glare Tester CGT-1000 for contrast sensitivity and glare testing in normal individuals and cataract patients. J Refract Surg 2007; 23(5): 492-8.

[14] Price MO, Fairchild KM, Price FW Jr. Comparison of manual and automated endothelial cell density analysis in normal eyes and DSEK eyes. Cornea 2013; 32(5): 567-73.

[15] Bellucci R. Multifocal intraocular lenses. Curr Opin Ophthalmol 2005; 16(1): 33-7.

[16] Tomita M, Kanamori T, Waring GO $4^{\text {th }}$, et al. Simultaneous corneal inlay implantation and laser in situ keratomileusis for presbyopia in patients with hyperopia, myopia, or emmetropia: Sixmonth results. J Cataract Refract Surg 2012; 38(3): 495-506.

[17] Petermeier K, Messias A, Gekeler F, Szurman P. Effect of +3.00 diopter and +4.00 diopter additions in multifocal intraocular lenses on defocus profiles, patient satisfaction, and contrast sensitivity. J Cataract Refract Surg 2011; 37(4): 720-6.

[18] Vaquero M, Encinas JL, Jimenez F. Visual function with monofocal versus multifocal IOLs. J Cataract Refract Surg 1996; 22(9): 1222-5

[19] Montés-Micó R, España E, Bueno I, Charman WN, Menezo JL. Visual performance with multifocal intraocular lenses: Mesopic contrast sensitivity under distance and near conditions. Ophthalmology 2004; 111(1): 85-96.

[20] Montés-Micó R, Alió JL. Distance and near contrast sensitivity function after multifocal intraocular lens implantation. J Cataract Refract Surg 2003; 29(4): 703-11

[21] Woodward MA, Randleman JB, Stulting RD. Dissatisfaction after multifocal intraocular lens implantation. J Cataract Refract Surg 2009; 35(6): 992-7.

[22] Santhiago MR, Wilson SE, Netto MV, et al. Modulation transfer function and optical quality after bilateral implantation of a +3.00 $\mathrm{D}$ versus a $+4.00 \mathrm{D}$ multifocal intraocular lens. J Cataract Refract Surg 2012; 38(2): 215-20.

[23] Charman WN, Montés-Micó R, Radhakrishnan H. Can we measure wave aberration in patients with diffractive IOLs? J Cataract Refract Surg 2007; 33(11): 1997.

[24] Kuroda T, Fujikado T, Maeda N, Oshika T, Hirohara Y, Mihashi T. Wavefront analysis of higher-order aberrations in patients with cataract. J Cataract Refract Surg 2002; 28(3): 438-44.

[25] Charman WN, Montés-Micó R, Radhakrishnan H. Problems in the measurement of wavefront aberration for eyes implanted with diffractive bifocal and multifocal intraocular lenses. J Refract Surg 2008; 24(3): 280-6. 